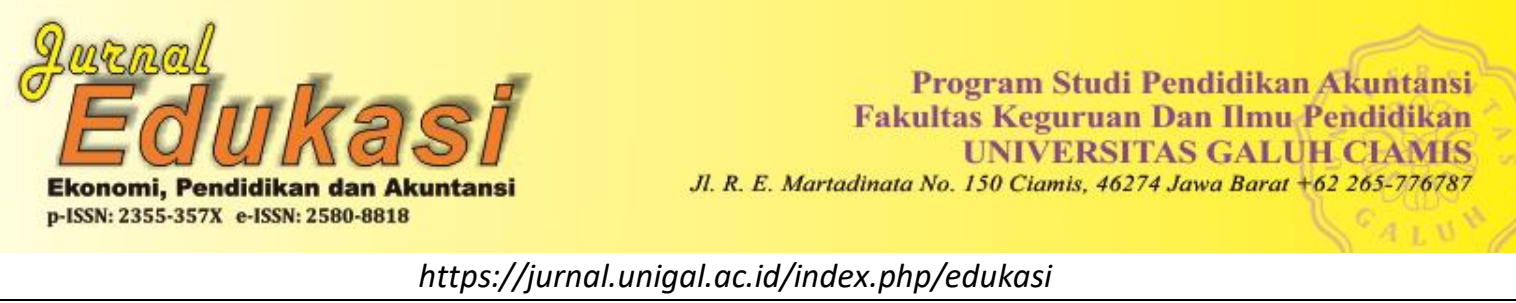

\title{
PERANAN LAYANAN TERPADU PENANGGULANGAN KEMISKINAN DAERAH (LTPKD) DALAM MENINGKATKAN KESEJAHTERAAN MASYARAKAT
}

\author{
Oleh: \\ Yuyun Susanti ${ }^{1}$, Nur Rizqi Arifin ${ }^{2}$ \\ Prodi Pendidikan Akuntansi Universitas Galuh \\ Email : yuyunsusanti444@gmail.com ${ }^{\mathbf{1}}$, \\ Email : nur.rizqi88@gmail.com ${ }^{2}$ \\ Sejarah Artikel: Diterima September 2019, Disetujui Oktober 2019, Dipublikasikan November 2019
}

\begin{abstract}
ABSTRAK
Latar belakang penelitian ini adalah masih tingginya angka kemiskinan di Kabupaten Ciamis sehingga diperlukannya program pengentasan penanggulangan kemiskinan dan tata kelola pemerintahan dimana keduanya saling berkaitan satu sama lain. Tujuan penelitian ini adalah untuk menganalisis Peranan Layanan Terpadu Penanggulangan Kemiskinan Daerah (LTPKD) dalam Meningkatkan Kesejahteraan Masyarakat di Kabupaten Ciamis. Metode penelitian yang digunakan adalah penelitian kualitatif, dengan menggunakan metode deskriptif. Teknik pengumpulan data dilakukan dengan observasi, wawancara, dan analisis berbagai dokumen yang berkaitan dengan judul yang diteliti. Hasil penelitian ini menunjukan bahwa terdapat peranan Layanan Terpadu Penanggulangan Kemiskinan Daerah (LTPKD) dalam meningkatkan kesejahteraan masyarakat di Kabupaten Ciamis, sehingga angka kemiskinan setiap tahun di Kabupaten Ciamis mengalami penurunan.
\end{abstract}

Kata Kunci: LTPKD, Kemiskinan, Kesejahteraan, Kabupaten Ciamis.

\section{ABSTRACK}

The background of this research is the high poverty rate in Kabupaten Ciamis so that the need for poverty alleviation and governance programs are both interrelated. The purpose of this study was to analyze Layanan Terpadu Penanggulangan Kemiskinan Daerah (LTPKD) in Improving Community Welfare in Kabupaten Ciamis. The research method used is qualitative research, using descriptive methods. Data collection techniques carried out by observation, interviews, and analysis of various documents relating to the title under study. The results of this study indicate that there is a role for Layanan Terpadu Penanggulangan Kemiskinan Daerah (LTPKD) in improving the welfare of the community in Kabupaten Ciamis, so that the poverty rate every year in Kabupaten Ciamis has decreased.

Keywords: LTPKD, Poverty, Welfare, Ciamis Regency

\section{PENDAHULUAN}

Krisis ekonomi di Indonesia yang terus berlangsung mulai tahun 1997 telah menimbulkan pemikiran kembali tentang pengentasanpenanggulangan kemiskinan. Tingkat pertumbuhan ekonomi yang tinggi di Indonesia yang berlangsung sekitar 30 tahun telah berhasil menurunkan angka kemiskinan absolut secara signifikan. Mulai tahun 1970-an hingga awal 1990-an, angka kemiskinan berhasil diturunkan sebesar 50 persen. Namun, sejak krisis berlangsung mulai pertengahan 1997, angka kemiskinan naik dua kali lipat, sehingga menghapus prestasi tersebut, dan 
membuat upaya pengentasanpenanggulangan kemiskinan kembali menjadi sesuatu yang mendesak untuk dilaksanakan dengan serius (Suryahadi, 2008).

Pekerjaan masyarakat Kabupaten Ciamis yang terbanyak adalah sebagian besar bekerja berada di sektor pertanian dengan status pekerjaan sebagai buruh tani yang sewaktuwaktu bisa menganggur (44,48\% RTS), disusul di sektor perdagangan ( $11,57 \%$ RTS), industri (4,57\%), bangunan $(4,46 \%$ RTS), penerima pendapatan $(24,44 \%)$ dan lain-lain sebesar (10,53\%). Jumlah "lain-lain" tersebut belum diketahui secara pasti apakah "lain-lain" itu berarti penganggur atau setengah penganggur atau pekerja lain. (http://www.sapa.or.id).

Pemerintah Kabupaten Ciamis untuk membuat Layanan Terpadu Penanggulangan Kemiskinan Daerah (LTPKD) yang disetujuai oleh Kementerian Sosial Republik Indonesia. Konsep pelaksanaan program/kegiatan pelayanan dan penanganan penanggulangan kemiskinan secara terpadu meliputi aspek pendidikan, kesehatan, sosial dan ekonomi serta data dan informasi; (Peraturan Bupati Ciamis Nomor 62 Tahun 2014).

Pemerintah Kabupaten Ciamis mengalami masalah baik dari sisi regulasi maupun tata laksana terkait penyaluran Dana Hibah dan Bantuan Sosial, proses pelaksanaan administrasi penyaluran dana hibah dan bantuan sosial masih dilakukan secara manual dan tertutup. Terdapat beberapa kelemahan dalam menyalurkan dana tersebut kepada masyarakat dan organisasi masyarakat, antara lain kelemahan dalam perencanaan dan proposal, pertanggungjawaban fiktif, pemotongan dana oleh panitia, realisasi yang tidak sesuai peruntukan, dan adanya penerima dana bansos yang sama. Masyarakat Kabupaten Ciamis sulit / tidak mengetahui kepada siapa dana hibah dan bansos disalurkan, berapa dana yang disalurkan kepada penerima, apa bentuk kegiatannya dan bagaimana bentuk pertanggungjawabannya. Untuk menanggulangi hal tersebut di atas, maka peran LTPKD berperan dalam mengawasi, mendata dan mendorong masyarakat untuk bangkit bersama dalam meningkatkan tarap hidup masyarakat dalam penanggulangan kemiskinan secara terpadu meliputi aspek pendidikan, kesehatan, sosial dan ekonomi serta data dan informasi.

\section{METODE PENELITIAN}

Metode penelitian yang dilakukan dalam penelitian ini adalah penelitian kualitatif, dengan menggunakan metode deskriptif. Penelitian kualitatif adalah penelitian yang pemecahan masalahnya menggunakan data empiris atau sebuah proses inquiry yang menyelidiki masalah-masalah sosial dan kemanusiaan dengan tradisi metodologi yang berbeda. Peneliti membangun sebuah gambaran yang kompleks dan holistic, menganalisa katakata, melaporkan pandangan atau opini para informan, dan keseluruhan studi berlangsung dalam latar situasi alamiah wajar (natural setting) (Masyhuri, 2011: 25).

\section{Sumber Penelitian}

Sumber data dalam penelitian ini berupa sumber data primer dan sumber data sekunder yang berasal dari para informan yang memberikan informasi sesuai dengan kebutuhan peneliti.

\section{Teknik Pengumpulan}

Data Teknik pengumpulandata dalam penelitian ini melalui observasi, wawancara dan dokumentasi.

\section{Instrumen Penelitian}

Dalam penelitian kualitatif, instrumen utamanya adalah peneliti itu sendiri, namun selanjutnyasetelah fokus penelitian menjadi jelas, maka kemungkinan akan dikembangkan intrumen penelitian lainnya.

\section{Uji Kredibilitas Data}

Uji kredibilitas data dalam penelitian ini menggunakan ketekunan pengamatan, trianggulasi, dan kecukupan referensi.

\section{Teknik Analisis Data}

Teknik analisis data yang digunakan dalam penelitian ini adalah mengacu pada konsep Milles \& Huberman (1992: 20) yaitu interactive model yang mengklasifikasikan analisis data dalam tiga langkah, yaitu Reduksi data (Data Reduction), Penyajian data (Data Display), dan Penarikan kesimpulan (Verifikasi) Untuk menguji keabsahan data yang didapat sehingga benar-benar sesuai dengan tujuan dan maksud penelitian, maka peneliti menggunakan teknik triangulasi. Triangulasi data adalah teknik pemeriksaan data yang memanfaatkan sesuatu yang lain diluar data tersebut untuk keperluan pengecekan atau 
sebagai pembanding data tersebut (Moleong, 2007: 330). Teknik uji keabsahan lain yang digunakan oleh peneliti adalah perpanjangan keikutsertaan.

\section{HASIL PENELITIAN DAN PEMBAHASAN}

Ciamis sebagai salah satu Kabupaten di provinsi di Jawa Barat, letaknya di sebelah Utara berbatasan dengan Kabupaten Majalengka dan Kabupaten Kuningan, sebelah Barat dengan Kabupaten Tasikmalaya dan Kota Tasikmalaya, sebelah Timur dengan Kota
Banjar dan Propinsi Jawa Tengah, dan sebelah Selatan dengan Kabupaten Pangandaran. Berdasarkan letak geogerafisnya Kabupaten Ciamis berada pada posisi strategis yang dilalui jalan Nasional lintas Provinsi Jawa Barat Provinsi Jawa Tengah dan jalan Provinsi lintas Ciamis-Cirebon-Jawa Tengah. Letak astronomisnya berada pada $108^{\circ} 20^{\prime}$ sampai dengan $108^{\circ} 40^{\prime}$ Bujur Timur dan $7^{\circ} 40^{\prime} 20^{\prime \prime}$ sampai dengan 7041'20', Lintang Selatan. Luas wilayah Ciamis sebesar 244,479 $\mathrm{Ha}$ atau 7,73 persen dari total luas daratan Propinsi Jawa Barat. (https://jabar.bps.go.id, Januari 2019).

\section{Tabel 1}

Data Indeks Pembangunan Manusia (IPM) Provinsi Jawa Barat 2010-2017 Indeks Pembangunan Manusia (IPM) Provinsi Jawa Barat 2010-2017

\begin{tabular}{|c|c|c|c|c|c|c|c|c|}
\hline \multirow{2}{*}{ Kab/Kota } & \multicolumn{8}{|c|}{ Indeks Pembangunan Manusia (IPM) } \\
\hline & 2010 & 2011 & 2012 & 2013 & 2014 & 2015 & 2016 & 2017 \\
\hline 3200 JAWA BARAT & 66,15 & 66,67 & 67,32 & 68,25 & 68,80 & 69,50 & 70,05 & 70,69 \\
\hline 3201 Bogor & 64,35 & 64,78 & 65,66 & 66,74 & 67,36 & 67,77 & 68,32 & 69,13 \\
\hline 3202 Sukabumi & 60,69 & 61,14 & 62,27 & 63,63 & 64,07 & 64,44 & 65,13 & 65,49 \\
\hline 3203 Cianjur & 58,58 & 59,38 & 60,28 & 61,68 & 62,08 & 62,42 & 62,92 & 63,70 \\
\hline 3204 Bandung & 67,28 & 67,78 & 68,13 & 68,58 & 69,06 & 70,05 & 70,69 & 71,02 \\
\hline 3205 Garut & 60,23 & 60,55 & 61,04 & 61,67 & 62,23 & 63,21 & 63,64 & 64,52 \\
\hline 3206 Tasikmalaya & 60,21 & 61,05 & 61,69 & 62,40 & 62,79 & 63,17 & 63,57 & 64,14 \\
\hline 3207 Ciamis & 64,64 & 65,48 & 66,29 & 67,20 & 67,64 & 68,02 & 68,45 & 68,87 \\
\hline 3208 Kuningan & 64,40 & 65,04 & 65,60 & 66,16 & 66,63 & 67,19 & 67,51 & 67,78 \\
\hline 3209 Cirebon & 63,64 & 64,17 & 64,48 & 65,06 & 65,53 & 66,07 & 66,70 & 67,39 \\
\hline 3210 Majalengka & 62,30 & 62,67 & 63,13 & 63,71 & 64,07 & 64,75 & 65,25 & 65,92 \\
\hline 3211 Sumedang & 66,04 & 66,16 & 67,36 & 68,47 & 68,76 & 69,29 & 69,45 & 70,07 \\
\hline 3212 Indramayu & 60,86 & 61,47 & 62,09 & 62,98 & 63,55 & 64,36 & 64,78 & 65,58 \\
\hline 3213 Subang & 63,54 & 64,21 & 64,86 & 65,48 & 65,80 & 66,52 & 67,14 & 67,73 \\
\hline 3214 Purwakarta & 64,93 & 65,51 & 66,30 & 67,09 & 67,32 & 67,84 & 68,56 & 69,28 \\
\hline 3215 Karawang & 64,58 & 65,21 & 65,97 & 66,61 & 67,08 & 67,66 & 68,19 & 69,17 \\
\hline 3216 Bekasi & 67,58 & 68,66 & 69,38 & 70,09 & 70,51 & 71,19 & 71,83 & 72,63 \\
\hline 3217 Bandung Barat & 61,34 & 62,36 & 63,17 & 63,93 & 64,27 & 65,23 & 65,81 & 66,63 \\
\hline 3218 Pangandaran & - & - & - & 64,73 & 65,29 & 65,62 & 65,79 & 66,60 \\
\hline 3271 Kota Bogor & 71,25 & 71,72 & 72,25 & 72,86 & 73,10 & 73,65 & 74,50 & 75,16 \\
\hline 3272 Kota Sukabumi & 67,94 & 68,67 & 69,74 & 70,81 & 71,19 & 71,84 & 72,33 & 73,03 \\
\hline 3273 Kota Bandung & 77,49 & 78,13 & 78,30 & 78,55 & 78,98 & 79,67 & 80,13 & 80,31 \\
\hline 3274 Kota Cirebon & 70,74 & 71,49 & 71,97 & 72,27 & 72,93 & 73,34 & 73,70 & 74,00 \\
\hline 3275 Kota Bekasi & 76,77 & 77,48 & 77,71 & 78,63 & 78,84 & 79,63 & 79,95 & 80,30 \\
\hline 3276 Kota Depok & 76,66 & 76,96 & 77,28 & 78,27 & 78,58 & 79,11 & 79,60 & 79,83 \\
\hline 3277 Kota Cimahi & 73,76 & 74,41 & 74,99 & 75,85 & 76,06 & 76,42 & 76,69 & 76,95 \\
\hline 3278 Kota Tasikmalaya & 66,58 & 67,18 & 67,84 & 68,63 & 69,04 & 69,99 & 70,58 & 71,51 \\
\hline 3279 Kota Banjar & 66,81 & 67,15 & 67,53 & 68,01 & 68,34 & 69,31 & 70,09 & 70,79 \\
\hline
\end{tabular}

Sumber: https://jabar.bps.go.id, Januari 2019

Berdasarkan table di atas, bahwa Indeks Pembangunan Manusia (IPM) di Kabupaten Ciamis dari tahun 2010 sampai dengan tahun 2017 sebagai berikut: Pada tahun 2010 sebesar 64,64\%, tahun 2011 sebesar 65,48\%, tahun 2012 sebesar 66,29\%, tahun 2013 sebesar 67,20\%, tahun 2014 sebesar 67,64\%, tahun 2015 sebesar 68,02, tahun 2016 sebesar 68,45\% dan tahun 2017 sebesar 68,87\%. 
Dengan demikian bahwa setiap tahun mengalami peningkatan untuk semua factor; bidang pendidikan, kesehatan, ekonomi dan daya beli masyarakat di Kabupaten Ciamis.

Tabel 2

Data Indikator Makro

Laju Pertumbuhan Penduduk di Kabupaten Ciamis

\begin{tabular}{|c|c|c|c|c|c|c|}
\hline No & Indikator & 2013 & 2014 & 2015 & 2016 & 2017 \\
\hline 1 & Laju Inflasi (\%) & 7.21 & 7.47 & 3.07 & 2.75 & 4.16 \\
\hline \multirow[t]{3}{*}{2} & Penduduk Miskin & & & & & \\
\hline & 1. Jumlah (orang) & $100,804.00$ & $99,810.00$ & $104,870.00$ & $98,770.00$ & $96,760.00$ \\
\hline & 2. Persentase $(\%)$ & 8.72 & 8.59 & 8.98 & 8.42 & 8.2 \\
\hline \multirow[t]{4}{*}{3} & Indikator Ketenagakerjaan & & & & & \\
\hline & $\begin{array}{l}\text { 1. Angkatan Kerja } \\
\text { (Orang) }\end{array}$ & $556,762.00$ & $555,648.00$ & $531,235.00$ & $543,369.00$ & $634,932.00$ \\
\hline & $\begin{array}{l}\text { 2. Tingkat Pengangguran } \\
\text { Terbuka (TPT) }\end{array}$ & 6.4 & 5.39 & 6.99 & 6.95 & 5.17 \\
\hline & $\begin{array}{l}\text { 3. Tingkat Kesempatan } \\
\text { Kerja (TKK) }\end{array}$ & 93.6 & 94.61 & 93.01 & 93.05 & 94.83 \\
\hline \multirow[t]{3}{*}{4} & $\begin{array}{l}\text { 1. Garis Kemiskinan } \\
\text { (Rupiah/Kapita) }\end{array}$ & $213,000.00$ & $229,000.00$ & $296,674.00$ & $319,150.00$ & $334,038.00$ \\
\hline & $\begin{array}{l}\text { 2. Indeks Kedalaman } \\
\text { Kemiskinan (P1) }\end{array}$ & 1.28 & 1.38 & 1.31 & 1.17 & 0 \\
\hline & $\begin{array}{l}\text { 3. Indeks Keparahan } \\
\text { kemiskinan (P2) }\end{array}$ & 0.29 & 0.31 & 0.3 & 0.27 & 0 \\
\hline 5 & Gini Ratio & 0.33 & 0.31 & 0.33 & 0.33 & 0.36 \\
\hline \multirow[t]{8}{*}{6} & $\begin{array}{l}\text { Indeks Pembangunan } \\
\text { Manusia (IPM) }\end{array}$ & 67.2 & 67.64 & 68.02 & 68.45 & 68.87 \\
\hline & 1. Indeks Pendidikan & 61.39 & 62.49 & 62.58 & 63.08 & 65.24 \\
\hline & $\begin{array}{l}\text { 1.1. Angka Harapan Lama } \\
\text { Sekolah (Tahun) }\end{array}$ & 13.46 & 13.57 & 13.59 & 13.65 & 13.66 \\
\hline & $\begin{array}{l}\text { 1.2. Angka Rata-rata Lama } \\
\text { Sekolah (Tahun) }\end{array}$ & 7.2 & 7.44 & 7.45 & 7.59 & 8.03 \\
\hline & 2. Indeks Kesehatan & 77.37 & 77.45 & 78.06 & 78.31 & 78.57 \\
\hline & $\begin{array}{l}\text { 2.1. Angka Harapan Hidup } \\
\text { (tahun) }\end{array}$ & 70.29 & 70.34 & 70.74 & 70.9 & 71.07 \\
\hline & 3. Indeks Pengeluaran & 63.87 & 63.93 & 64.43 & 64.92 & 65.73 \\
\hline & $\begin{array}{l}\text { 3.1. Daya Beli Masyarakat } \\
\text { (Rp.) }\end{array}$ & $8,147,000.00$ & $8,162,000.00$ & $8,296,000.00$ & $8,342,000.00$ & $8,658,000.00$ \\
\hline 7 & $\begin{array}{l}\text { Laju pertumbuhan } \\
\text { Ekonomi }(\%)\end{array}$ & 5.34 & 5.07 & 5.59 & 5.99 & 5.21 \\
\hline 8 & $\begin{array}{l}\text { PDRB atas dasar harga } \\
\text { berlaku (Juta Rp.) }\end{array}$ & $18,674,942.50$ & $20,395,461.43$ & $22,588,229.06$ & $24,524,451.40$ & $26,544,477.00$ \\
\hline 9 & $\begin{array}{l}\text { PDRB atas dasar konstan } \\
\text { (Juta Rp.) }\end{array}$ & $16,026,514.20$ & $16,839,415.64$ & $17,779,912.89$ & $18,844,973.53$ & $19,826,747.90$ \\
\hline 10 & $\begin{array}{l}\text { PDRB Perkapita atas } \\
\text { dasar harga berlaku (Rp.) }\end{array}$ & $16,162,190.60$ & $17,550,491.60$ & $19,327,951.50$ & $20,864,965.90$ & $22,457,617.40$ \\
\hline 11 & $\begin{array}{l}\text { PDRB Perkapita atas } \\
\text { dasar harga konstan (Rp.) }\end{array}$ & $13,870,113.80$ & $14,490,479.90$ & $15,213,644.90$ & $16,032,967.40$ & $16,774,168.00$ \\
\hline
\end{tabular}

Sumber: http://bappeda.ciamiskab.go.id/Data.php Tahun 2019

Berdasarkan tabel di atas bahwa fokus pada angka kemiskinan setiap tahunnya yaitu sebagai berikut: pada tahun 2013 angka kemiskinan di Kabupaten Ciamis sebesar 8,72\%, pada tahun 2014 sebesar 8,59\%, pada tahun 2015 sebesar 8,98\%, pada tahun 2016 sebesar 8,42\% dan pada tahun 2017 sebesar $8,2 \%$. Dengan demikian angka kemiskinan di Kabupaten Ciamis mengalami penurunan dari tahun ketahun. 


\section{HASIL PENELITIAN DAN PEMBAHASAN}

Berdasarkan hasil penelitian yang dilakukan oleh peneliti, Tentang Peranan Layanan Terpadu Penanggulangan Kemiskinan Daerah (LTPKD) Dalam Meningkatkan Kesejahteraan Masyarakat Di Kabupaten Ciamis yang meliputi empat aspek yaitu:

1. Adanya koordinasi yang baik antara pihak pemerintah dengan masyarakat dalam pelaksanaan program/kegiatan pelayanan dan penanganan penanggulangan kemiskinan secara terpadu meliputi aspek pendidikan, kesehatan, sosial dan ekonomi serta data dan informasi di Kabupaten Ciamis. Pelaksanaan program yang dilakukan oleh pemerintah Kabupaten Ciamis terkait dengan penanggulangan kemiskinan secara terpadu meliputi aspek pendidikan, kesehatan, sosial dan ekonomi berdasarkan LAKIP Laporan Kinerja Instansi Pemerintah Kabupaten Ciamis untuk Tahun Anggaran 2017 yang diterbitkan pada tahun 2018. Berdasarkan data yang telah peneliti kumpulkan bahwa rat-rata angka kemiskinan setiap tahunnya mengalami penurunan.

2. Adanya pelaksanaan dan pendampingan sehingga pemantauan dan evaluasi pelaksanaan kebijakan oleh pemerintahan daerah dalam penanggulangan kemiskinan; pelayanan administrasi penanggulangan kemiskinan di Kabupaten Ciamis berjalan baik dan penekanan angka kemiskinan setiap tahunnya menurun.

3. Berfungsinya bagian penanganan pengaduan masyarakat terhadap program/kegiatan penanggulangan kemiskinan; pengkajian, penghimpunan dan pembaharuan (updating database) kemiskinan di Kabupaten Ciamis. Kepala daerah mengakui bahwa terdapat warga miskin oleh karena itu peran pemerintah dalam meninjau kembali data tersebut untuk kesahihannya demi tercipta kesejahteraan masyarakat. Kepala daerah mengakui adanya warga miskin dan membuat pogram kemiskinan. Peran pemerintah mendata ulang dan mau mengakui ada warga miskin dan melakukan upaya penanggulangan yang dilakukan oleh LTPKD. Pemda mempersiapkan segala aspek dan sistem yang menunjang tercapainya program pemberantasan kemiskinan.

4. Adanya peranan layanan terpadu penanggulangan kemiskinan daerah (LTPKD) dalam meningkatkan kesejahteraan masyarakat di Kabupaten Ciamis, sehingga angka kemiskinan setiap tahun di Kabupaten Ciamis mengalami penurunan yaitu pada tahun 2013 sebesar 8,72\%, pada tahun 2014 sebesar $8,59 \%$, pada tahun 2015 sebesar $8,98 \%$, pada tahun 2016 sebesar 8,42\% dan pada tahun 2017 sebesar 8,2\%.

\section{KESIMPULAN \\ Simpulan}

Berdasarkan hasil penelitian yang dilakukan oleh peneliti tentang Peranan Layanan Terpadu Penanggulangan Kemiskinan Daerah (LTPKD) Dalam Meningkatkan Kesejahteraan Masyarakat di Kabupaten Ciamis dapat disimpulkan sebagai berikut:

1. Adanya koordinasi yang baik antara pihak pemerintah dengan masyarakat dalam pelaksanaan program/kegiatan pelayanan dan penanganan penanggulangan kemiskinan secara terpadu meliputi aspek pendidikan, kesehatan, sosial dan ekonomi serta data dan informasi di Kabupaten Ciamis.

2. Adanya pelaksanaan dan pendampingan sehingga pemantauan dan evaluasi pelaksanaan kebijakan oleh pemerintahan daerah dalam penanggulangan kemiskinan; pelayanan administrasi penanggulangan kemiskinan di Kabupaten Ciamis berjalan baik dan penekanan angka kemiskinan setiap tahunnya menurun.

3. Berfungsinya bagian penanganan pengaduan masyarakat terhadap program/kegiatan penanggulangan kemiskinan; pengkajian, penghimpunan dan pembaharuan (updating database) kemiskinan di Kabupaten Ciamis.

4. Terdapat peranan layanan terpadu penanggulangan kemiskinan daerah (LTPKD) dalam meningkatkan kesejahteraan masyarakat di Kabupaten Ciamis, sehingga angka kemiskinan setiap tahun di Kabupaten Ciamis mengalami penurunan yaitu pada tahun 
2013 sebesar 8,72\%, pada tahun 2014 sebesar 8,59\%, pada tahun 2015 sebesar $8,98 \%$, pada tahun 2016 sebesar $8,42 \%$ dan pada tahun 2017 sebesar 8,2\%. Dengan demikian angka kemiskinan di Kabupaten Ciamis mengalami penurunan dari tahun ketahun.

\section{Saran}

1. Sebaikan pelaksanaan koordinasi pelaksanaan program/kegiatan pelayanan dan penanganan penanggulangan kemiskinan secara terpadu lebih di optimalkan sehingga aspek pendidikan, kesehatan, sosial dan ekonomi serta data dan informasi di Kabupaten Ciamis dapat ditingkatkan.

2. Sebaiknya pemantauan dan evaluasi pelaksanaan kebijakan pemerintahan daerah dalam penanggulangan kemiskinan ditingkatkan dengan melibatkan berbagai unsur pemerintah daerah dan peran serta masyarakat agar pelayanan administrasi penanggulangan kemiskinan di Kabupaten Ciamis lebih baik.

3. Sebaiknya penanganan pengaduan masyarakat terhadap program/kegiatan penanggulangan kemiskinan di Kabupaten Ciamis tetap dipertahankan peran dan fungsi bahkan ditingkatkan dalam pengkajian, penghimpunan dan pembaharuan (updating database) kemiskinan di Kabupaten Ciamis agar angka kemiskinan menurun sehingga IPM meningkat.

4. Sebaiknya peranan layanan terpadu penanggulangan kemiskinan daerah (LTPKD) di Kabupaten Ciamis ditingkatkan dan dipertahankan walaupun adanya pergantian kepala daerah agar sehingga kesejahteraan masyarakat di Kabupaten Ciamis lebih baik.

\section{DAFTAR PUSTAKA}

Masyhuri dan Zainuddin, M. 2011. Metodologi Penelitian: Pendekatan Praktis dan Aplikasi. Bandung: Refika Aditama.

Miles, B. Mathew dan Michael Huberman. 1992. Analisis Data Kualitatif Buku Sumber Tentang Metode-metode Baru. Jakarta: UIP.

Moleong, Lexy J. 2007. Metodologi Penelitian Kualitatif. Bandung: Penerbit PT Remaja Rosdakarya Offset.
Peraturan Bupati Ciamis Nomor 62 Tahun 2014

$$
\begin{array}{llr}
\text { Tentang Layanan } & \text { Terpadu } \\
\text { Penanggulangan } & \text { Kemiskinan } & \text { Daerah } \\
\text { (LTPKD). } & &
\end{array}
$$

http://bappeda.ciamiskab.go.id/Data.php Tahun 2019

https://jabar.bps.go.id, Januari 2019

http://www.sapa.or.id diakses 04 Januari 2018 Pukul 18.47 WIB. 